
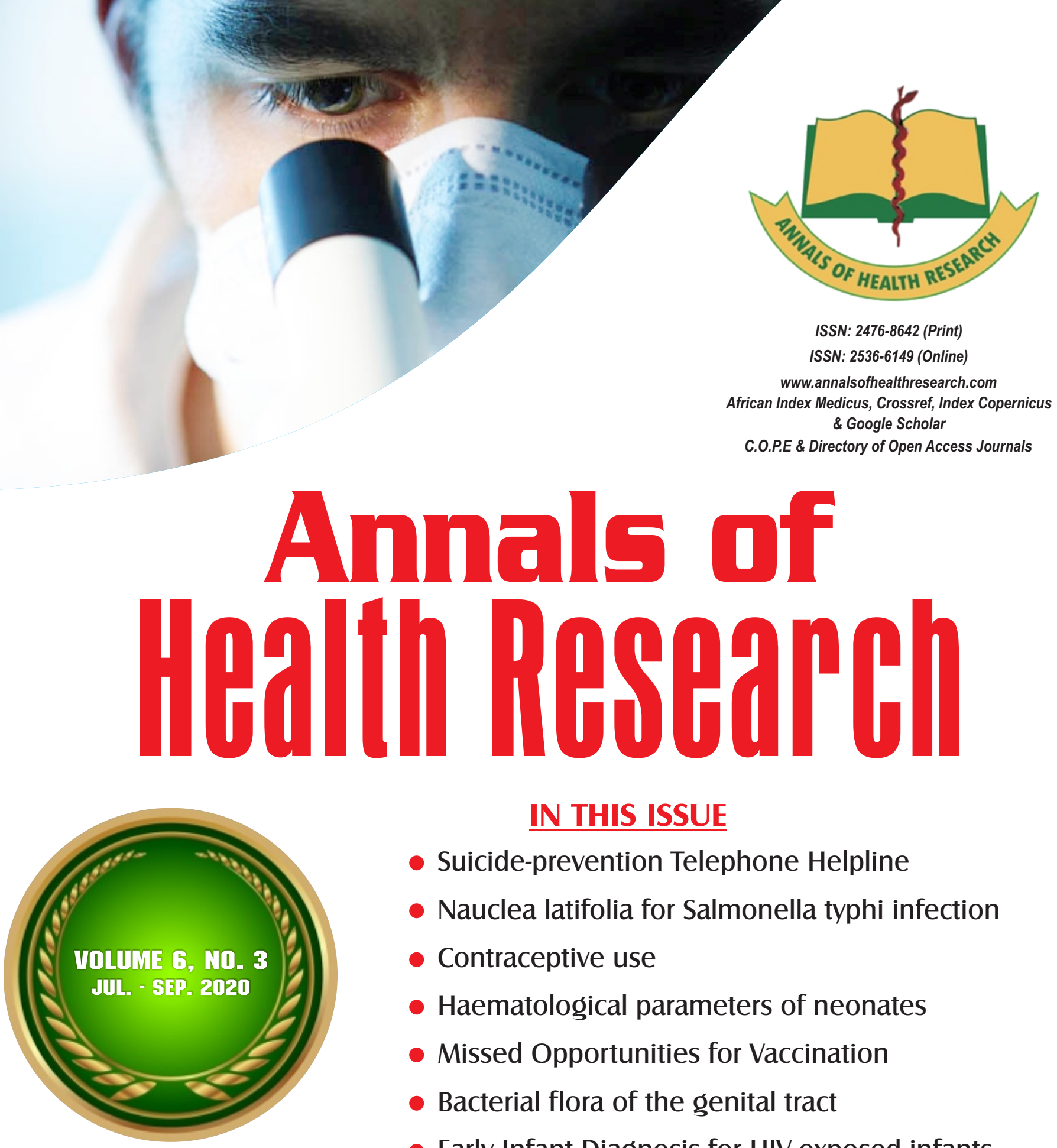

IN THIS ISSUE

- Suicide-prevention Telephone Helpline

- Nauclea latifolia for Salmonella typhi infection

- Contraceptive use

- Haematological parameters of neonates

- Missed Opportunities for Vaccination

- Bacterial flora of the genital tract

- Early Infant Diagnosis for HIV-exposed infants

- Bone markers and cardiovascular risk factors

- Attitude to termination of pregnancies

- Herpes zoster ophthalmicus

- Neonatal hyperinsulinaemic hypoglycaemia

- Paediatric perineal injury

PUBLISHED BY THE MEDICAL

AND DENTAL CONSULTANTS ASSOCIATION

OF NIGERIA, OOUTH, SAGAMU, NIGERIA.

www.mdcan.oouth.org.ng 


\title{
The pattern of crisis calls to a suicide telephone helpline service in Nigeria
}

\section{Ogbolu RE ${ }^{1}$, Oyatokun $\mathrm{BO}^{* 1}$, Ogunsola $\mathrm{K}^{1}$, Quadri $\mathrm{O}^{1}$, Adegbite TA ${ }^{1}$, Tade $\mathrm{T}^{2}$, Olafisoye $\mathrm{O}^{1}$, Aina $\mathrm{OF}^{1}$ (Suicide Research and Prevention Initiative)}

1Department of Psychiatry, ${ }^{2}$ Department of Medical Social Works, Lagos University Teaching Hospital, Idi-Araba, Lagos, Nigeria

*Correspondence: Dr BO Oyatokun, Department of Psychiatry, Lagos University Teaching Hospital, Idi-Araba, Lagos, Nigeria. E-mail: bolutifeoyatokun@yahoo.com; ORCID - https://orcid.org/0000-0003-4100-7682.

\begin{abstract}
Background: Suicide is the deliberate killing of oneself. Although it is preventable, suicide accounts for over 800,000 global deaths annually. There is the need to scale-up prevention strategies, and one of these strategies is the provision of suicide telephone helplines.

Objectives: To describe the pattern of calls received by a suicide telephone helpline and the types of intervention provided in a Nigerian facility.

Methods: This was a descriptive study of the first 100 completed calls received on a 24-hour suicide telephone helpline service by trained responders.

Results: All the calls emanated from 14 states of the federation, with the majority (83.0\%) from the Southern parts of the country. The reasons for the telephone calls varied from crisis situations $(47.0 \%)$ to telephone number-verification $(27.0 \%)$, mental health information $(20.0 \%)$, and others $(6.0 \%)$. The mean age of the crisis -situation callers was 25.8 years, with a slight female preponderance $(53.2 \%)$; most were single in marital status (68.1\%) and unemployed (70.2\%). A majority (72.3\%) of the callers had an underlying mental condition, $68.1 \%$ had suicidal ideation while $12.8 \%$ had previously attempted suicide. All the crisis callers were offered interventions ranging from phone counselling to linkage to the nearest mental health services.

Conclusion: A majority of the crisis callers were offered mental health services, raising the possibility that the availability of telephone helplines may play a role in suicide prevention in Nigeria.
\end{abstract}

Keywords: Crisis Intervention, Mental health, Suicide, Telephone Helpline.

\section{Introduction}

Suicide, the deliberate act of killing oneself, is a global issue and it is estimated to account for $1.5 \%$ of global deaths translating to over 800,000 deaths annually across the globe. ${ }^{[1,2]}$ It has been reported that for every suicidal death, there have been suicidal attempts by 20 to 25 people. [3] This translates to about 20-25 million attempted suicides annually. Since a previous suicidal attempt is a strong predictor of suicide, $[2,4]$ the provision of support to previous suicide 
attempters as well as other at-risk groups [1,5,6] when in crisis is critical.

One way by which vulnerable people can seek help when in crisis is through the use of telephone helplines. This approach dates back to the anti-suicide bureau of the Salvation Army in the United Kingdom in the early 1900s. [6]

Helpline interventions for suicide prevention can be approached from the active-listening model where the listener shows attention through skills such as asking questions to seek clarification, summarizing, reflecting on what the caller says, and the use of words or phrases that show positive reinforcement. The other model is the collaborative problem-solving model, where the listener works with the caller to solve problems through the exchange of ideas, perspectives and information. [7-9] The shortage of mental health personnel ${ }^{[10,11]}$ and the rising teledensity level in the country [12] make telephone intervention an attractive option to use in reaching people in need. [7-9] The use of the telephone as a means of mental health intervention may also help overcome the issue of stigma, including self-stigmatization. [13, 14] Asides providing crisis intervention services, telephone helplines, like other effective prevention strategies, can also be used to disseminate appropriate and accurate mental health information and even to follow-up patients. $[15,16]$

The lifetime prevalence of suicidal ideation, plan and attempt in Nigeria is put at 3.2\%, 1.0\% and $0.7 \%$ respectively. [17] This indicates that an approach targeted at those with ideation and plans may reduce their likelihood of eventually committing suicide. This could be a sizeable number of individuals in a country with a $12.1 \%$ lifetime prevalence of mental disorders ${ }^{[18]}$ and a population of close to two hundred million, with a large proportion of youths. [19] Given the earlier report that less than $20 \%$ of African countries have data on suicide, ${ }^{[5]}$ worsened by the low access to healthcare services due to several factors including low finances, [20] any strategy that helps bridge this gap ${ }^{[10,11]}$ through telephony should be impactful. This is particularly imperative considering that most people who attempt suicide will have given a warning, or exhibited other often-ignored behaviours. [6, 21-24]

This study examined the pattern of crisis telephone calls received by a suicide telephone helpline available in Nigeria, a country with a suicide rate of 9.5 per $100,000,[3]$ and the types of crisis interventions provided in preventing suicide. The need to provide data on suicide telephone helpline calls in the country prompted the need for this study with the expectation that it may shed more light on the issue of suicide as well as the role of information and communications technology (ICT) in the reduction of suicide rates. It is hoped that the information provided by the study will help improve the current prevention strategies.

\section{Methods}

\section{Study location and setting}

The telephone helpline location was the Lagos University Teaching Hospital, situated in the urban, cosmopolitan city of Lagos. The hospital, in the year 2017, established the Suicide Research and Prevention Initiative (SURPIN), which provides crisis and suicide prevention services through telephone helpline services. A 24-hour telephone helpline service with phone numbers covering the four major networks in the country was established. The phone numbers were widely disseminated through social media, print media, as well as through featured television and radio programmes syndicated across the country. The telephone lines are manned by doctors with a minimum of three years training in psychiatry and 
supervised by a consultant psychiatrist, who also mans one of the phone lines 24 hourly.

The call responders with training in psychiatry were sufficiently experienced in psychiatric symptomatology and the making of diagnosis based on the International Classification of Diseases-10 ${ }^{\text {th }}$ version (ICD-10) ${ }^{[25]}$ and other diagnostic standards. They were also trained in the use of Schedules for Clinical Assessment in Neuropsychiatry (SCAN). [26]

\section{Design}

It was a descriptive study of all the telephone calls received in the first year of operation of the telephone helpline, between April 2017 and March 2018. The data from the first one hundred completed calls made during this period were reported in this study. Truncated or incomplete calls (those that were too short to obtain reasonable information, dropped calls due to network connection problems, calls where the caller declined to give enough information or where there was a need for language interpreter were excluded. Ethical approval was obtained from the Research and Ethics Committee of the residential institution. Limited identifier-data were collected but they were securely stored.

\section{Data collection and instruments}

Information was gathered using a specificallydesigned call data entry form which included questions on basic socio-demographic profile and suicide-related inquiry (See Appendix). Depending on the urgency and reason for the call, appropriate callers were interviewed for depression or drug abuse over the phone, or at a later scheduled date based on ICD-10 ${ }^{[25]}$ criteria or using the relevant sections of SCAN interview. [26] This interview was conducted at the SURPIN office in the hospital, or at any of its collaborating centres that the caller had been referred to. The diagnoses were verified by consultant psychiatrists who reviewed the cases or received the calls.

\section{Data Analysis}

The Statistical Package for Social Sciences SPSS [27] (version 22) was used for the analysis of categorical and continuous data. The ChiSquare test and frequency tables were used to interpret and present the data where applicable.

\section{Results}

Geographic distribution of the phone calls

The telephone calls were received from 14 states of the federation, with $17.0 \%$ from the northern part of the country (including 6\% from the Federal Capital Territory), and $83.0 \%$ from the southern part of the country $(78.0 \%$ from the South-west region and $5.0 \%$ from the Southeast/South-south geo-political zones) as shown in Table I.

\section{Reasons for the calls}

The reasons for calling the telephone helplines included crises $(47.0 \%)$, the need to verify the numbers $(27.0 \%)$, to seek information on mental health $(20.0 \%)$, and others $(6.0 \%)$ which included calls unrelated to health, as well as prank calls (Table I).

\section{Crisis calls}

Socio-demographic characteristics of crisis calls

Crisis calls were made by people who were either feeling severely depressed or suicidal or needed urgent help for drug use disorders. There were 47 crisis calls in all. There was a slight female preponderance (53.2\%). The mean age of the crisis callers was 25.8 years with most of them aged 20-29 years (51.1\%) and 30-39 years (29.8\%) (Table II). The callers were mostly Christians (85.1\%), single in marital status $(68.1 \%)$ and unemployed (70.2\%); of these, $23.4 \%$ were students. 
Table I: Distribution of the location of callers and reasons for 100 telephone calls

\begin{tabular}{llll}
\hline Variables & & Frequency & Percentage \\
\hline Location of callers & Lagos & 77 & 77.0 \\
& FCT & 6 & 6.0 \\
& Other South-west States & 1 & 1.0 \\
& Northern states & 11 & 11.0 \\
& South-east/South-south states & 5 & 5.0 \\
& & & \\
Reasons for calls & Crisis & 47 & 47.0 \\
& To seek information & 20 & 20.0 \\
& To verify telephone number & 27 & 27.0 \\
& Other forms of assistance & 6 & 6.0 \\
\hline
\end{tabular}

FCT-Federal Capital Territory

Identifiable stressors

Identifiable stressors included financial difficulty $(27.7 \%)$, relationship issues $(19.1 \%)$, health-related problems $(12.8 \%)$, academic problems (12.8\%), and work-related issues $(10.6 \%)$. There was no identifiable stressor in $17.0 \%$ of cases (Table III).

\section{Underlying Mental Health Condition}

Following the evaluation, the leading underlying mental health condition included major depressive disorder (44.6\%) and substance use disorders (23.4\%), mostly opioid use disorders including prescription opioids such as tramadol (Table III).

\section{Suicide ideation and past suicide attempts}

Suicide ideation was present in $68.1 \%$ of the crisis callers and $12.8 \%$ of them had previously attempted suicide (Table III). More females (42.6\%) had suicidal ideation compared to males $(25.5 \%)$ and $57.4 \%$ of those with suicidal ideation had not previously attempted suicide, compared to $10.6 \%$ who had. Suicidal ideation was 5 times commoner among those with previous suicide attempts compared to those with no previous attempts $(10.6 \%$ vs $2.1 \%)$ as shown in Table IV.

Major depression was the commonest mental health condition among those with suicidal ideation (42.6\% of crisis callers) and this finding was statistically significant $(p<0.001)$. Past suicide attempt was commoner among female callers $(10.6 \%)$ compared to males $(2.1 \%)$, and major depression was the only diagnosis among those with past suicide attempts as shown in Table V.

\section{Interventions offered to callers}

The majority $(85.1 \%)$ of the callers were provided meaningful crisis intervention towards suicide prevention; these ranged from linkage to nearby mental health services $(66.0 \%)$ to visits to the SURPIN Operational Base for a free evaluation (19.1\%). Other interventions included telephone counselling and linkages to other needed services $(14.9 \%)$ (Table III). The specialists at the referral centres gave feedback that the callers referred to them were seen. This is a positive intervention.

\section{Discussion}

Almost half $(47 \%)$ of the first one hundred calls were made by people in crises. This underscores the importance of crisis interventions in the country. The populace also seems to need an avenue to easily access information relating to 
health, because $20 \%$ of the calls in this study sought health information. Coveney et al., [28] had similarly reported that callers used their service for various reasons and that it often formed part of a support network for some.

Table II: Socio-demographic characteristics of 47 crisis callers

\begin{tabular}{llll}
\hline Characteristics & & Frequency & Percentage \\
\hline Age groups (Years) & $\leq 12$ & 2 & 4.3 \\
& $13-29$ & 1 & 2.1 \\
& $20-29$ & 24 & 51.1 \\
& $30-39$ & 14 & 29.8 \\
& $40-49$ & 5 & 10.6 \\
& $\geq 50$ & 1 & 2.1 \\
Sex & Male & & \\
& Female & 22 & 46.8 \\
Religion & Christianity & 40 & 53.2 \\
& Islam & 5 & 85.1 \\
& Others & 2 & 10.6 \\
Marital status & Single & 32 & 4.3 \\
& Married & 11 & 68.1 \\
& Separated/Divorced & 4 & 23.4 \\
Occupation & Unemployed & 33 & 8.5 \\
& Employed & 14 & 70.2 \\
\hline
\end{tabular}

The wide distribution of crisis calls from fourteen states of the federation shows that despite the country's ethnic diversity, there is a common need for telephone helpline services. A large number of the phone calls were made from Lagos (an urban megacity and the nation's commercial capital) and this may be because the awareness about the initiative's telephone helplines started, and is perhaps most penetrative, in Lagos.

The crisis calls were made mostly by young adults between aged $20-29$ years and $30-39$ years. This is not unexpected because the country has a rather young demographic. ${ }^{[29]}$ The former age-group falls within the 15-29 year age-range among which suicide has been reported to be the second leading cause of death. [1, 2] The slight preponderance of female among crisis callers suggests they may seek help more compared to males. Iqbal et al., [30] had similarly reported almost equal sex distribution with similarity in age distribution; the 20 -39 years group formed the majority of callers in the fiveyear study of suicide prevention helpline in Bangladesh. Nigeria and Bangladesh are developing countries and they may share some general similarities.

The finding that the callers were mostly single and unemployed conforms to the findings from other studies that have identified these to be risk factors. [5] Single (unmarried) persons may be less likely to receive emotional supports from a confidant, and perhaps feel isolated. This has been identified as a risk for suicide, especially among older adults. [31] 
Table III: Correlates of crisis telephone calls

\begin{tabular}{|c|c|c|c|c|}
\hline \multicolumn{3}{|l|}{ Variables } & \multirow{2}{*}{$\begin{array}{l}\text { Frequency } \\
8\end{array}$} & \multirow{2}{*}{$\begin{array}{l}\text { Percentage } \\
17.0\end{array}$} \\
\hline Identifiable stressor & & None & & \\
\hline & & Financial difficulties & 13 & 27.7 \\
\hline & & Relationship issues & 9 & 19.1 \\
\hline & & Health-related problems & 6 & 12.8 \\
\hline & & Academic problems & 6 & 12.8 \\
\hline & & Others & 5 & 10.6 \\
\hline \multirow{2}{*}{\multicolumn{2}{|c|}{ Suicidal ideation }} & Present & 32 & 68.1 \\
\hline & & Absent & 15 & 31.9 \\
\hline \multirow{2}{*}{\multicolumn{2}{|c|}{ Suicidal attempt }} & Present & 6 & 12.8 \\
\hline & & Absent & 41 & 87.2 \\
\hline \multirow{3}{*}{\multicolumn{2}{|c|}{ Intervention Plan }} & Linked to mental health services & 31 & 66.0 \\
\hline & & Visited the centre for evaluation & 9 & 19.1 \\
\hline & & $\begin{array}{l}\text { Others (phone counselling, linkages } \\
\text { etc) }\end{array}$ & 7 & 14.9 \\
\hline \multirow{4}{*}{$\begin{array}{l}\text { Underlying } \\
\text { conditions }\end{array}$} & health & None & 13 & 27.7 \\
\hline & & Major depression & 21 & 44.6 \\
\hline & & Substance abuse disorders & 11 & 23.4 \\
\hline & & Others & 2 & 4.3 \\
\hline
\end{tabular}

Table IV: Relationship between suicidal ideation and sex, underlying mental health conditions and suicide attempt

\begin{tabular}{|c|c|c|c|c|c|c|c|c|c|}
\hline \multicolumn{3}{|l|}{ Characteristics } & \multicolumn{7}{|c|}{ Suicidal ideation } \\
\hline & & & \multicolumn{2}{|c|}{$\begin{array}{l}\text { Present } \\
(\mathrm{n}=32)\end{array}$} & \multicolumn{2}{|c|}{$\begin{array}{l}\text { Absent } \\
(\mathrm{n}=15)\end{array}$} & \multicolumn{2}{|c|}{$\begin{array}{l}\text { Total } \\
(\mathrm{n}=47)\end{array}$} & \multirow[t]{2}{*}{ Statistics } \\
\hline & & & $\mathrm{n}$ & $\%$ & $\mathrm{~N}$ & $\%$ & $\mathrm{~N}$ & $\%$ & \\
\hline \multirow{2}{*}{\multicolumn{2}{|c|}{ Sex }} & Male & 12 & 37.5 & 10 & 66.7 & 22 & 46.8 & $\chi^{2}=3.489$ \\
\hline & & Female & 30 & 62.5 & 5 & 33.3 & 25 & 53.2 & $p=0.062$ \\
\hline \multirow{4}{*}{\multicolumn{2}{|c|}{$\begin{array}{l}\text { Underlying } \\
\text { conditions }\end{array}$}} & None & 10 & 31.2 & 3 & 20.0 & 13 & 27.7 & $\chi^{2}=25.512$ \\
\hline & & Major depression & 20 & 62.6 & 1 & 6.7 & 21 & 44.7 & $\mathrm{p}<0.001$ \\
\hline & & $\begin{array}{l}\text { Substance abuse } \\
\text { disorders }\end{array}$ & 1 & 3.1 & 10 & 66.6 & 11 & 23.3 & \\
\hline & & Others & 1 & 3.1 & 1 & 6.7 & 2 & 4.3 & \\
\hline \multirow{2}{*}{\multicolumn{2}{|c|}{ Suicide attempt }} & Yes & 5 & 15.6 & 1 & 6.7 & 6 & 12.8 & $\chi^{2}=0.736$ \\
\hline & & No & 27 & 84.4 & 14 & 93.3 & 41 & 78.2 & $p=0.648$ \\
\hline
\end{tabular}


Table V: Relationship between suicide attempt and sex and underlying mental health conditions

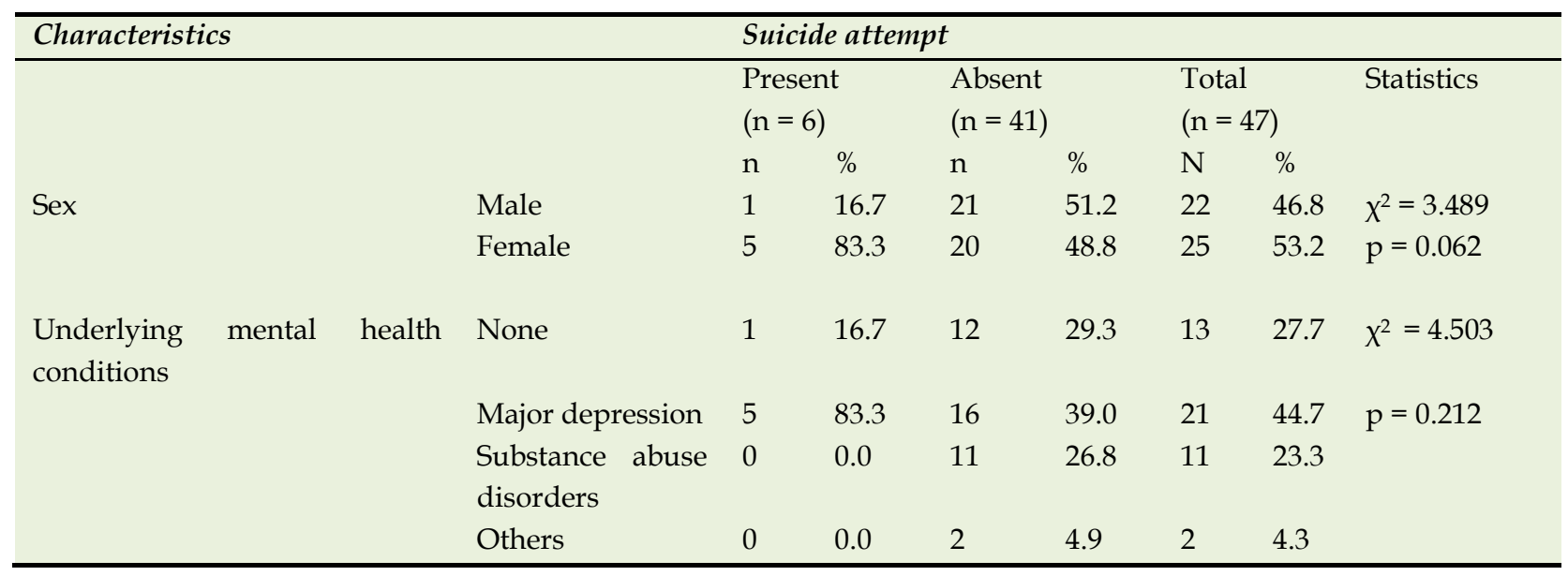

Financial difficulties were the commonest identifiable stressors among the callers, probably related to the predominant unemployment status of the crisis callers; employment can also impact on self-fulfilment, as has been found in other studies on the suicide-related crisis. [5, 21] Relationship issues were the second commonest stressor among the callers, similar to previous reports. ${ }^{5,30]}$

In keeping with some previous studies that reported suicidal ideation and attempt rates of $20 \%$ and $12 \%$ respectively among children and adolescents in Nigeria, ${ }^{[32]}$ almost a quarter of the callers in the present study were students $(23.4 \%)$. The explanation for this may not be farfetched, because most callers were in the younger age group, most of whom may be students. Furthermore, other studies found that most suicides occurred among Nigerians below 30 years of age. [33]

The presence of suicidal ideation among twothirds of the crisis callers underscores the importance of interventions targeting those with suicidal ideation, especially because about twothirds of them will have a plan to commit suicide. [17] It is not surprising that suicidal ideation was five times higher in those who had previously attempted suicide since major depression was the commonest diagnosis amongst them. The value of exploring and addressing suicidal ideation becomes all the more pertinent in the effort to reduce suicide rates. The present study found that suicidal ideation, and to an even greater extent, suicide attempts, were commoner among the female callers, similar to the reports by Villanueva et al, in Spain. [34] This may be in keeping with the almost ubiquitous finding that females are more likely to have depression and to attempt suicide, even though males are more likely to commit suicide, with higher suicide rates among them. [34] Shrivastava and colleagues, [36] reported a lower level $(15.4 \%)$ of suicidal ideation in their study, compared to the present study, probably because they reported on a community-based clinic with a telephone helpline.

The link between suicide and depression has been reported severally in the literature [1, 3, 21] and this was observed in the present study. The association between suicide and substance use disorders has also been frequently reported. [1, 4- 
6] Most $(72.3 \%)$ of the crisis callers in the present study had an underlying mental health condition which is mostly treatable; this implies that adequate and effective treatment of mental health conditions like depression will contribute considerably towards the goal of reducing suicide nationwide, $[2,6,15,16,21,23]$ and reducing the global suicide rate by $10 \%$ by the year 2020 . $[2,4-6]$ This is encouraged by the fact that the telephone helpline provided a platform and an opportunity to offer help to the callers as $81.5 \%$ of them were provided intervention by physical attendance at either the suicide prevention initiative office or mental health services nearest to them.

Research on crisis telephone helplines is sparse in developing countries, and more research will certainly be required to evaluate its impact, [30] considering that about $85 \%$ of suicides reportedly occur in Low- and Middle-Income Countries, [2] and suicide telephone helplines can be a cost-effective means of suicide prevention. A limitation of this study lies in the fact that the telephone diagnosis of mental disorders among the callers was sometimes based solely on screening questions since it was difficult to fully administer diagnostic schedules. A larger number of subjects, albeit suicide-related, would have made for more robust analysis.

\section{Conclusion}

Major depression was the commonest condition among the crisis callers and majority of them were provided positive interventions; this shows that the use of telephone helplines can be a useful tool in suicide prevention. The present study also shows the value of creating more mental health awareness considering the other reasons why the helplines were called and the preponderance of calls from Lagos where there had been more publicity.
Acknowledgement: The authors acknowledge all the members of the Suicide Research and Prevention Initiative.

Authors' Contributions: ORE, OBO, OK, QO, ATA, $\mathrm{TT}, \mathrm{OO}$ and $\mathrm{AOF}$ contributed to the conception and design of the study and were involved in data collection. ORE and OBO did data analysis and interpretation, literature review, drafting of manuscripts and review of drafts. All the authors approved the final version of the manuscript.

Conflicts of interest: None declared.

Funding: Self-funded.

Publication History: Submitted 23 November 2019; Accepted 16 May 2020.

\section{References}

1. World Health Organization. Preventing Suicide: Global Imperative. Geneva; World Health Organization: 2014. Available from http://www.who.int/mental_health/suicid e-prevention/world_report_2014/en/ Accessed 31't May 2019.

2. World Health Organization. Mental Health. Suicide data. Available from http://www.who.int/mental_health/preve ntion/suicide/suicideprevent/en/ Accessed 30th May 2019.

3. World Health Organization. Global Health Observatory. Suicide rates per (100,000population) crude rates. Geneva: World Health Organization; 2014. Available from

http://www.who.int/gho/mental_health/s uicide_rates_crude/en/ Accessed 30th May 2019.

4. American Psychiatric Association. Practice guideline for the assessment and treatment of patients with suicidal behaviors. Arlington, VA: American Psychiatric Publishing; 2003. 
5. Mars B, Burrows S, Hjelmeland H, Gunnell D. Suicidal behaviour across the African continent: a review of the literature. BMC Public Health, 2014; 14: 606. doi:10.1186/1471-2458-14-606.

6. The Salvation Army. Hope For Life Suicide Prevention and Bereavement Support. Available from http:/ / www.suicideprevention.salvos.org.a u. Accessed 31'st May 2019.

7. Budinger MC, Cwik MF, Riddle MA. Awareness, attitudes, and use of crisis helplines among youth at-risk for suicide. Suicide Life-Threatening Behavior 2015; 45: 192-198. doi: 10.1111/sltb.12112.

8. Gould MS, Kalafat J, Harrismunfakh JL, Kleinman M. An evaluation of crisis helpline outcomes. Part 2: Suicidal callers. Suicide Life-Threatening Behavior 2007; 37: 338-352.

9. Mishara BL, Chagnon F, Daigle M, Balan B, Raymond S, Marcoux I, et al. Comparing Models of Helper Behavior to Actual Practice in Telephone Crisis Intervention: A Silent Monitoring Study of Calls to the U.S. 1-800-SUICIDE Network. Suicide LifeThreatening Behavior 2007; 37: 291-307. https://doi.org/10.1521/suli.2007.37.3.291

10. Klecha D, Barke A, Gurepe O. Mental Healthcare in developing countries: the example of Nigeria. Nervenarzt 2004; 75: 1118-1122. doi: 10.1007/s00115-003-1653-8.

11. Uwakwe R, Otakpor A. Public mental health- using the Mental Health Gap Action Program to put all hands to the pumps. Frontiers Public Health 2014; 2: 1-5. doi.10 3389/fpubh.2014.00033.

12. Nigerian Communications Commission. Nigeria has achieved 100 per cent teledensity. The Communicator 2018;2 4(1). Available from https://www.ncc.gov.ng/thecommunicator /index.php?option $=$ com_content\&view $=$ arti cle\&id=888:nigeria-has-achieved-100-
percent-teledensity\&catid=25\&Itemid $=179$. Accessed 31 ${ }^{\text {st }}$ May 2019.

13. Armiyau AY. A Review of Stigma and Mental Illness in Nigeria. J Clin Case Reports 2015; 5: 488. doi:10.4172/2165-7920.1000488. https://www.omicsonline.org/openaccess/a-review-of-stigma-and-mentalillness-in-nigeria-21657920.1000488.php?aid=40679

14. Ukpong DI, Abasiubong DI. Stigmatizing attitudes towards the mentally ill: A survey in a Nigerian university teaching hospital. South Afr J Psychiatry 2010; 16: 56-60. http://dx.doi.org/10.4102/sajpsychiatry.v16 i2.238.

15. Roscoat E, Beck F. Efficient interventions on suicide prevention: A literature review. J Epidemiol Public Health 2013; 61: 363-374. https://doi.org/10.1016/j.respe.2013.01.099.

16. Zalsman G, Hawton $K$, Wasserman D, van Heeringen D, Arensman E, Sarchiapone M, et al. Suicide prevention strategies revisited: 10-year systematic review. Lancet Psychiatry 2016; 6: 646-659. doi: 10.1016/S22150366(16)30030-X.

17. Gureje O, Kola L, Uwakwe R, Udofia O, Wakil A, Afolabi E. The profile and risks of suicidal behaviours in the Nigerian Survey of Mental Health and Well-Being. Psychol Med 2007; 37: 821-830. doi: 10.1017/S0033291707000311.

18. Gureje O, Lasebikan V, Kola L, Makanjuola $\mathrm{V}$. Lifetime and 12-month prevalence of mental disorders in the Nigerian Survey of Mental Health and Well-Being. Brit J Psychiatry 2006; 188: 465-471. doi: 10.1192/bjp.188.5.465.

19. National Bureau of Statistics. Nigeria Population. (2018-09-24). Available 2019-0306, from http://worldpopulationreview.com/countri es/nigeria/ Accessed on 6 $6^{\text {th }}$ March 2019. 
20. Uzochukwu BSC, Ughasoro MD, Etiaba E, Okwuosa C, Envuladu E, Onwujekwe OE. Healthcare financing in Nigeria: Implications for achieving universal health coverage. Niger J Clin Pract 2015; 18: 437-444.

21. Adewuya A, Ola B, Coker O, Atilola O, Zachariah $\mathrm{M}$, Olugbile $\mathrm{O}$, et al. Prevalence and associated factors for suicidal ideation in the Lagos State Mental Health Survey in Lagos, Nigeria. Brit J Psychiatry Open 2016; 2: 385-389. doi: 10.1192/bjpo.bp.116.004333.

22. Alabi OO, Alabi AI, Ayinde OO, Abdulmalik JO. Suicide and Suicidal Behaviour in Nigeria: A Review. Journal of University of Ibadan Medical Students Association. 2014; 37:

12-16.

https://www.researchgate.net/publication/ 271748010_Suicide_and_Suicidal_Behavior_i n_Nigeria_A_review.

23. Nwafor CC, Akhiwu WO, Igbe AP. Review of Suicidal Deaths seen in a Nigerian Tertiary Health Institution. Pioneer Med J 2013; 3: 1-8.

24. Vijayakumar L, Nagaraj K, Pirkis J, Whiteford $H$. Suicide in developing countries 1: frequency, distribution, and association with socioeconomic indicators. Crisis 2015; 26: 104-111. doi: 10.1027/02275910.26.3.104.

25. World Health Organization. The ICD-10 Classification of Mental and Behavioural Disorders: Clinical descriptions and guidelines. Geneva: Oxford University Press; 1992.

26. Rijnders CA, van den Berg JF, Hodiamont PP, Nienhuis FJ, Furer JW, Mulder J, et al. Psychometric properties of the schedules for clinical assessment in neuropsychiatry (SCAN-2.1). Social Psychiatry Psychiatric Epidemiol 2000; 35: 348-352.

27. Levesque R. SPSS Programming and Data Management. A Guide for SPSS and SAS Users, $4^{\text {th }}$ ed. Chicago, Ill: SPSS Inc; 2007.
28. Coveney CM, Pollock K, Armstrong S, Moore J Callers' experiences of contacting a national suicide prevention helpline: Report of an online survey. Crisis: The Journal of Crisis Intervention and Suicide Prevention $2012 \quad 33$ 313-324. doi:http://dx.doi.org/10.1027/02275910/a000151.

29. CIA World Factbook. Nigeria Demographics Profile 2019. Available from https://www.indexmundi.com/nigeria/de mographics_profile.html. Accessed 331st May 2019.

30. Iqbal Y, Jahan R, Matin MR. Descriptive characteristics of callers to emotional support and suicide prevention helpline in Bangladesh (first five years). Asian J Psychiatry 2019; 45: 63-65.

31. Chan $\mathrm{CH}$, Wong HK, Yip PSF. Exploring the use of telephone helpline pertaining to older adult suicide prevention: A Hong Kong experience. J Affective Disorders 2018; 236: 75-79.

32. Omigbodun O, Dogra N, Esan O, Adedokun B. Prevalence and Correlates of Suicidal Behaviour among Adolescents in Southwest Nigeria. Int J Social Psychiatry 2008; 54: 3446.

https://doi.org/10.1177/0020764007078360.

33. Odejide AO, Williams AO, Ohaeri JU, Ikuesan BA. The epidemiology of deliberate self-harm. The Ibadan experience. Brit J Psychiatry 1986; 149: 734-737. https://doi.org/10.1192/bjp.149.6.734.

34. Villanueva P, Arteaga A, FernándezMontalvo J. Gender differences in risk factors related to suicidal ideation among callers to telephone helplines in Spain. Arch Suicide Res 2018; 23: 605-615.

35. World Health Organization (WHO): Depression and Other Common Mental Disorders. Global Health Estimates (2017). 
Accessed

$11 / 15 / 2107$

http://www.who.int/mental_health/mana

gement/depression/prevalence_global_heal

th_estimates/en/
36. Shrivastava AK, Johnston ME, Stitt L, Thakar M, Sakel G, Iyer S, et al. Reducing treatment delay for early intervention: evaluation of a community based crisis helpline. Ann Gen Psychiatry 2012; 11: 20. https://doi.org/10.1186/1744-859X-11-20. () $(1 \otimes)$

This is an Open Access document licensed for distribution under the terms and conditions of the Creative Commons Attribution License (http://creativecommons.org/licenses/by-nc/4.0). This permits unrestricted, non-commercial use, reproduction and distribution in any medium provided the original source is adequately cited and credited. 


\section{APPENDIX}

\section{Call Data Form}

Phone No:

1. Name (Initials):

2. Date of call:

3. Time of call:

4. Age:

5a. Sex:

5b.Marital status:

6. Religion:

7. Occupation:

8. Call location (state/LGA)

9. Purpose of the call:

10a. Suicidal ideation:

10b: If present:

11. Suicide attempt:

12. No. of previous attempts:

13. Method of previous attempts:

14. Present plan:

15. If present, type of plan:

16. Method being planned:

17. Stressors (give as many details):

18. Are there underlying medical conditions?

19. Are there features of depression:

20. Past psychiatric history/condition:

21. Significant contact:

22. Plan/intervention (Phone counselling/link to mental health service/visit SURPIN/provide mental health information/etc):

23. Need for follow-up:

24. Caller agrees to follow-up call:

25. State intended date for follow up call:

26. Level of suicide risk (no risk/low/medium/high):

27: How did caller get to know about SURPIN?

(Television/Radio/Online/Facebook/Twitter/Instagram/Referral):

28. Additional information: 